\title{
Tiempos de cambio y pandemia en Latinoamérica Perspectivas y desafíos de las políticas culturales uruguayas*
}

\author{
Times of change and pandemics in Latin America \\ Perspectives and challenges of Uruguayan cultural policies
}

FEDERICO SEQUEIRA / VICTORIA LEMBO**

\begin{abstract}
This article aims to give an account of the challenges and perspectives of Uruguayan cultural policies in the face of two recent factors of change in Latin America: changes in the political sign of governments and the COVID-19 pandemic. In this text there is an analysis through the approach to theoretical concepts of policies and cultural rights, the inaugural speeches of the Uruguayan presidents Vázquez (progressive) and Lacalle Pou (liberal), their programs, and the current budgetary project; as well as an additional analysis of the regional situation and the pandemic through press articles. Considering the current moment of Latin American, from the Uruguayan case we could point out that the government's new orientation would seem to face a paradigm shift in the conception of cultural policies and rights. In that sense, in the institutional changes proposed by the government, its cultural conception seems to be weighed against the consolidation of tools that - in this context of uncertainty and pandemic - strengthen the sector.
\end{abstract}

Key words: progressism, neoliberalism, COVID-19, cultural rights, cultural citizenship, cultural institutionality

\begin{abstract}
Resumen
Este artículo se propone dar cuenta de los desafíos y perspectivas de las políticas culturales uruguayas frente a dos factores de cambio recientes en Latinoamérica: los cambios de signo político de los gobiernos y la pandemia de la COVID-19. Mediante el abordaje de conceptos teóricos sobre políticas y derechos culturales, se analizarán los discursos inaugurales de los presidentes uruguayos Vázquez (progresista) y Lacalle Pou (liberal), sus programas y el actual proyecto de presupuesto. La coyuntura regional y la pandemia se examinarán a través de artículos de prensa. Con base en la actual coyuntura latinoamericana, y a partir del caso uruguayo, se señalará que la nueva orientación del gobierno parecería enfrentarnos a un cambio de paradigma en la concepción de las políticas y derechos culturales. Asimismo, en los cambios institucionales propuestos por el gobierno, parece ponderarse su concepción cultural frente a la consolidación de herramientas que -en este contexto de incertidumbre y pandemia-fortalezcan al sector cultural.
\end{abstract}

Palabras clave: progresismo, neoliberalismo, COVID-19, derechos culturales, ciudadanía cultural, institucionalidad cultural

\footnotetext{
* Artículo recibido el 25/03/20 y aceptado el 08/05/20.

** Universidad de la República, Centro Universitario Regional Este. Tacuarembó entre Bvar. Artigas y Av. Aparicio Saravia, 20100 Punta del Este, Departamento de Maldonado, Uruguay <fsequeira@cure.edu.uy>, <victorialembo@gmail.com>.
} 


\section{Introducción}

$\mathrm{E}$ 1 presente artículo tiene como objetivo informar sobre posibles perspectivas y desafíos de las políticas culturales (PPCC) y los derechos culturales (DDCC) del Uruguay, revisando sus fortalezas y debilidades, frente a dos factores de cambio regional: por un lado, el cambio de signo político en la orientación de los gobiernos de Argentina (2015) Brasil (2016) y Uruguay (2019) y, por el otro, la irrupción regional en 2020 de la pandemia del coronavirus (COvid-19). En ese sentido, cabe plantearse cómo afectará esta situación a nuestras instituciones culturales nacionales en cuanto rectoras de políticas públicas.

Para el análisis de las PPCC y los DDCC en el Uruguay nos centraremos en los consensos propuestos por el nuevo gobierno y para qué tipo de orden o transformación social lo hará (García Canclini, 1987); cuál será la relación entre DDCC y políticas públicas (Achugar, 2003); si habrá un enfoque moral y político de los DDCC a la hora de diseñar las acciones y programas culturales (Nivón Bolán, 2017), o si se reconocerá la diversidad cultural al profundizar la descentralización de las PPCC (Carámbula, 2011).

De acuerdo con el objetivo planteado, como metodología de análisis se tendrán en cuenta conceptos teóricos específicos referidos a PPCC (García Canclini) y a DDCC (Achugar, Nivón, Carámbula). En cuanto al cambio de gobierno en Uruguay, se examinarán las menciones relacionadas con cultura, DDCC y PPCC en los discursos inaugurales de los presidentes Tabaré Vázquez (2005) del Frente Amplio (FA) y Luis Lacalle Pou (2020) del Partido Nacional (PN). En ese sentido, se investigarán también las propuestas programáticas del FA y del PN presentadas para las elecciones de 2019. Asimismo se tendrá en cuenta la Ley de Presupuesto Nacional que regirá para el periodo $2020-2024^{1} \mathrm{y}$ la Ley de Urgente Consideración (LUC). ${ }^{2}$ Respecto de la coyuntura regional y la pandemia de la COVID-19, el abordaje se realizará principalmente mediante la exploración de artículos de prensa.

El texto está estructurado en tres grandes bloques: Contexto regional: Argentina, Brasil y Uruguay; El caso uruguayo: las políticas culturales atravesadas por el cambio de gobierno y la pandemia, y Reflexiones finales. En el primero se alude a los cambios en la orientación ideológica de los Estados de la región, entre el neoliberalismo y el progresismo; se menciona también, en clave regional, la actual crisis generada por la pandemia de la COVID-19 y las transformaciones en las PPCC y su institucionalidad. Considerando su orientación ideológica y sus concepciones de cultura, PPCC, DDCC y dignidad humana, en el segundo se escudriñan posibles consecuencias que el reciente cambio de gobierno y la pandemia tendrán para la institucionalidad cultural uruguaya. Por último, en tercer lugar, se plantean, a modo de conclusión, posibles respuestas y perspectivas sobre las PPCC y los DDCC y se identifican algunos puntos críticos que están en el centro del debate cultural: ¿Qué Estados para qué derechos culturales? ¿Cuál será la relación entre esos Estados y sus ciudadanos? ¿Intervención del Estado o prescindencia? ¿Se fortalecerá una visión tradicional o renovadora en términos de valores culturales? ¿Cuál será la perspectiva de derechos pospandemia?

\section{Contexto regional: Argentina, Brasil y Uruguay}

\section{Estados latinoamericanos: entre el progresismo y el neoliberalismo}

Argentina, Brasil y Uruguay son naciones intrínsecamente relacionadas en términos históricos, socioculturales, económicos y políticos. Muchos cambios en nuestra región han operado casi en simultáneo en estos tres países. En ese sentido, como marco de referencia, nos interesa mencionar dos momentos de cambio regional: por un lado, la instauración del neoliberalismo en la década de los años setenta con las dictaduras de seguridad nacional (Hinkelammert, 1990) $\mathrm{y}$, por el otro, la irrupción de la llamada marea rosa (Rohter, 2005) con los gobiernos progresistas de comienzos del siglo xxI.

Según Elodie Bordat-Chauvin (2016), el neoliberalismo es el conjunto de teorías que han renovado, desde finales de los años treinta, el pensamiento económico liberal. Estas teorías critican el intervencionismo estatal porque entienden que limitan el mercado, la libertad individual y desaceleran la economía. El neoliberalismo, en cuanto teoría económica dominante, filosofía política y conjunto de creencias y representaciones mentales, se constituye como una ideología política.

En nuestra región-como periferia capitalista(Borón, 2001) - la crítica a la intervención estatal por parte de

1 Presupuesto Nacional 2020-2024 <https://www.gub.uy/ministerio-economia-finanzas/sites/ministerio-economiafinanzas / files/documentos/noticias/proyecto.pdf> [ 10 de septiembre de 2020].

2 Ley $\mathrm{N}^{\circ}$ 19889. Aprobación de la Ley de Urgente Consideración. Luc. Ley de Urgencia (14 de julio de2020) <https://www. impo.com.uy/bases / leyes / 19889-2020> [ 10 de septiembre de 2020]. 
gobiernos neoliberales -desde las dictaduras de los años setenta- se ha traducido en un debilitamiento de los Estados. Según Atilio Borón, nuestros Estados "se convirtieron en verdaderos 'tigres de papel' incapaces de disciplinar a los grandes actores económicos y, mucho menos, de velar por la provisión de los bienes públicos que constituyen el núcleo de una concepción de la ciudadanía” (Borón, 2001: 182).

En lo que respecta a las PPCC, el neoliberalismo también ha tenido sus efectos. Elodie Bordat-Chauvin (2016), al analizar Argentina y México, señala que en el caso mexicano los efectos neoliberales han sido mayores, porque desde la década de los ochenta todos los gobiernos han profundizado las políticas neoliberales. Mientras que en el caso argentino, dado que la política cultural está menos institucionalizada y depende de los cambios de gobierno, el neoliberalismo tuvo gran influencia en las PPCC de la década de los noventa, pero se redujo con el ascenso del kirchnerismo en 2003. La transferencia de competencias vinculadas a la administración cultural -por parte de los gobiernos neoliberales de ambos países- al sector privado revelan una reducción de la intervención estatal en las PPCC. Asimismo, el Tratado de Libre Comercio de América del Norte (TLCAN) ${ }^{3}$ generó cambios más drásticos en las PPCC mexicanas que los efectos que tuvo el Mercado Común del Sur (Mercosur) ${ }^{4}$ para las PPCC argentinas. Según la autora, la filosofía de acción de la "cultura como recurso económico" se ha instaurado desde los noventa, y en el caso argentino, con el kirchnerismo en 2003, apareció una nueva filosofía de acción (BordatChauvin, 2016).

El ascenso en 2003 tanto del peronista Néstor Kirchner en Argentina como del Partido dos Trabalhadores (PT) encabezado por Lula en Brasil, y en 2005 el del Frente Amplio (FA) en Uruguay, con Tabaré Vázquez al frente, forman parte de los ciclos de contestación que en América Latina las fuerzas progresistas articularon como respuesta social y política a una crisis percibida como consecuencia de la globalización neoliberal (Sanahuja, 2019).

Así fue que la izquierda regional, en un proceso de fortalecimiento del Estado, propició cambios en la integración latinoamericana e incorporó con mayor peso en su agenda las dimensiones sociales, políticas, de seguridad, energéticas y de infraestructura (Sanahuja, 2010).

Dichos procesos no estuvieron exentos de conflictos y tensiones, no obstante ello supusieron importantes avances. De ahí que, como propone Maristella Svam- pa al analizar la relación de los movimientos sociales con los gobiernos de izquierda en América Latina, "los cambios del escenario político regional [...] a partir del quiebre del consenso neoliberal, permiten pensar nuevas alternativas emancipatorias, más allá de las fuertes diferencias nacionales" (Svampa, 2006: 141).

El triunfo del liberal Mauricio Macri en Argentina en 2015, y el ascenso de Michel Temer tras la destitución de Dilma Rousseff en 2016 en Brasil marcaron el inicio de un nuevo giro en la orientación ideológica de los gobiernos regionales. Las elecciones nacionales brasileñas de 2018 reafirmaron esta nueva orientación con el triunfo de Jair Messias Bolsonaro y en la misma línea al año siguiente se produjo en Uruguay la victoria de Luis Lacalle Pou.

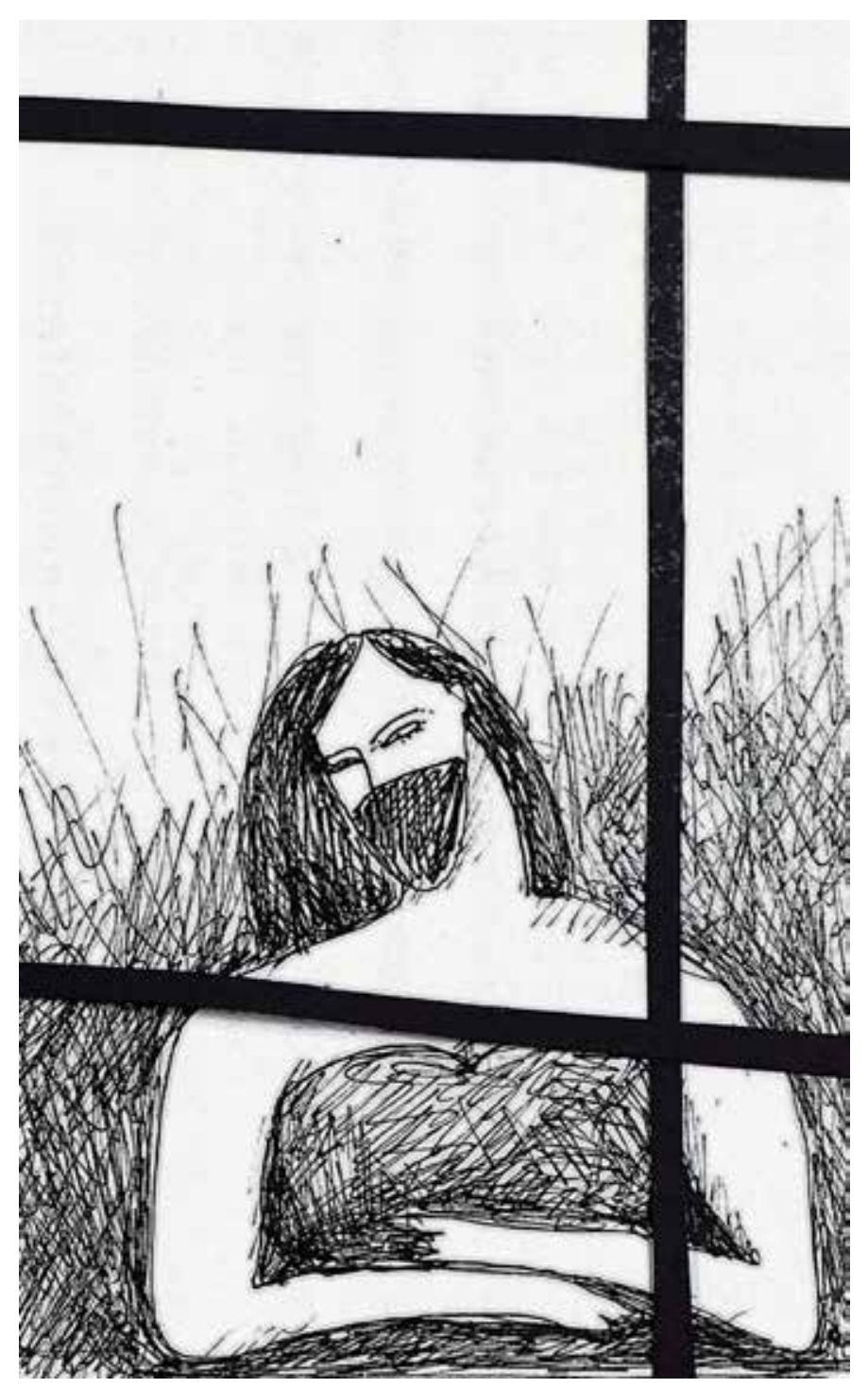

3 Canadá, Estados Unidos y México.

4 Argentina, Brasil, Paraguay, Uruguay y Venezuela (suspendida). 
En un análisis previo a las elecciones uruguayas de 2019, Caetano, Nieto y Sellos decían:

En Uruguay aparece con claridad que un triunfo de la oposición traerá cambios importantes en algunas de las principales políticas macroeconómicas implementadas en los últimos años y, en forma colateral, una revisión e implementación de nuevos modelos de gestión de las políticas sociales y laborales, como mínimo. En otro plano, pero no menos importante, es muy probable que un triunfo de la oposición traiga el desembarco de cambios en las políticas de seguridad interna así como en el diseño de las políticas de áreas claves como la educación y la salud pública. Recordemos que Uruguay es un país donde lo público es preeminente y cambios en estas políticas implican redistribuciones importantes entre los diferentes sectores de la sociedad [Caetano, Nieto y Sellos, 2020: 41].

Asimismo, en dicho análisis los autores sostienen que:

Uruguay está procesando en su sociedad un giro hacia visiones más críticas sobre el funcionamiento de la democracia y sobre los partidos políticos, a la vez que se eleva el prestigio de las Fuerzas Armadas y parece confirmarse un corrimiento general hacia posiciones más a la derecha, así como una erosión en el recelo tradicional hacia posturas militaristas y de "ultraderecha" [Caetano, Nieto y Sellos, 2020: 44].

Mientras Bolsonaro asumía la presidencia de Brasil y Lacalle Pou triunfaba en las elecciones uruguayas, a contracorriente, tras cuatro años de macrismo, ${ }^{5}$ en 2019 Argentina retornó al "progresismo" con la asunción del peronista-kirchnerista Alberto Fernández como presidente de la nación.

\section{La COVID-19 en la región}

Cuando nos propusimos hacer este artículo la enfermedad del coronavirus (COviD-19) aún parecía un "cuento chino", principalmente por la lejanía que Wuhan suponía. La realidad indica que la COVID-19 irrumpió y está golpeando con fuerza a nuestra región, produ- ciendo estados de excepción, cuarentenas obligatorias, recomendaciones de aislamiento, de distanciamiento social, amenazas a nuestros sistemas sanitarios y económicos y generando gran incertidumbre. Lo cierto es que el contexto regional y mundial cambió $\mathrm{y}$, aunque las medidas y la propia enfermedad quizá no sean permanentes, la región y el mundo no serán los mismos. En este tiempo, de búsqueda de explicaciones, Byung-Chul Han ha sostenido que frente a esta situación, en la cual cada uno está preocupado por sobrevivir, "la solidaridad consistente en guardar distancias mutuas no es una solidaridad que permita soñar con una sociedad distinta, más pacífica, más justa" (Byung-Chul Han, 2020: s/p). Por el contrario, en este sistema capitalista, lejos de haber recibido un "golpe letal”, como afirma Slavoj Žižek (2020), mientras cada uno está centrado y confiando demasiado en los gobiernos, como sostiene Naomi Klein, el capitalismo del desastre utiliza las crisis a gran escala para impulsar políticas que profundizan la desigualdad, enriquecen a las elites y debilitan a todos los demás (Klein, 2008). A decir de Judith Butler:

el fracaso de algunos estados o regiones para prepararse por anticipado [...], el refuerzo de las políticas nacionales y el cierre de fronteras [...], y la llegada de emprendedores ávidos de capitalizar el sufrimiento global, todo esto testimonia la velocidad con la cual la desigualdad radical $[\ldots]$, y la explotación capitalista encuentra formas de reproducirse y fortalecer sus poderes [Butler, 2020: s/p].

En este contexto cabe preguntarse ¿están preparados nuestros Estados para afrontar una crisis como ésta?, ¿cuánto han debilitado estos cambios políticos a nuestras instituciones?, ¿qué prioridades establecerán nuestros gobiernos? La dinámica de los acontecimientos hace que tengamos variadas contestaciones para estas preguntas, incluso con gobiernos que han dado más de una respuesta como es el caso del de Brasil: mientras el presidente hablaba de "gripecinha" su ministro de Salud recomendaba el aislamiento. ${ }^{6}$ Las consecuencias han sido un debilitamiento institucional -hace meses que Brasil no tiene ministro de Salud-y una situación descontrolada de la pandemia. ${ }^{7}$ En el caso argentino, de orientación progresista, su

5 Gobierno de la alianza "Cambiemos", encabezado por Mauricio Macri (2015-2019).

6 "El coronavirus causa una crisis en el gobierno de Bolsonaro", en La Diaria (4 de abril de 2020) <https://ladiaria.com. uy/articulo/2020/4/el-coronavirus-causa-una-crisis-en-el-gobierno-de-bolsonaro/> [ 10 de abril de 2020].

7 "Brasil, el segundo país más afectado por Covid, sin ministro de Salud", en Portafolio (23 de agosto de 2020) <https:// www.portafolio.co/internacional/brasil-el-segundo-pais-mas-afectado-por-covid-sin-ministro-de-salud-543897> [15 de septiembre de 2020]. 
solución ha sido el aislamiento social obligatorio. Si bien de esta manera se ha intentado cuidar el sistema sanitario para que no colapse, en la actualidad está al límite, y a esto se suman las tensiones de la política por el manejo de la crisis sanitaria. ${ }^{8}$ En el Uruguay se apeló al aislamiento social voluntario y a un conjunto de medidas que según parece han contenido la crisis sanitaria, pero no han alcanzado para mitigar una crisis social y económica que será tanto o más potente. Aparentemente, Estados fuertes han enfrentado con mayor éxito la pandemia. Así ocurre con Uruguay, donde, dada su amplia cobertura en salud ${ }^{9}$ o sus reservas internacionales, ${ }^{10}$ se registraron fortalezas en clave regional, si se compara con la situación del sistema sanitariobrasileño ${ }^{11}$ o el endeudamiento argentino con el Fondo Monetario Internacional (FMI). ${ }^{12}$

En este incierto escenario podríamos pensar que esta crisis será, como se dice popularmente, una oportunidad. Lo que no sabemos es si será como nos plantea Slavoj Žižek una oportunidad para "pensar en una sociedad alternativa, una sociedad más allá del Estado-nación, una sociedad que se actualiza a sí misma en las formas de solidaridad y cooperación global" (2020: 22) o, como parecería estar sucediendo, una oportunidad para profundizar la desigualdad y la exclusión. No sabemos qué consecuencias tendrá esto en una región tan desigual como la latinoamericana y con tantas dificultades para anticiparse a los avatares del mundo contemporáneo.

\section{Idas y vueltas de las políticas culturales en la región}

Las PPCC que fueron impulsadas por los gobiernos progresistas latinoamericanos de principios del siglo $\mathrm{xx}$ se sostuvieron en dos aspectos: el reconocimiento de los DDCC de los ciudadanos y la necesidad de Estados fuertes que los garanticen.

En un artículo que problematiza la existencia de un modelo sudamericano de política cultural y que revisa los casos de Chile, Paraguay y Uruguay se señala que la asunción de gobiernos progresistas en la región supuso el reto de desarrollar PPCC democratizadoras capaces de paliar las inequidades de acceso a la cultura. Según los autores se trataba de una nueva etapa de las PPCC, en la cual se reconoció su capacidad de generar una identidad nacional inclusiva, así como su contribución para el desarrollo social y económico equilibrado en el territorio (Zamorano, Rius Ulldemolins y Klein, 2014).

Desde esta perspectiva, podemos señalar que el documento programático "A imaginação a serviço do Brasil" (Partido dos Trabalhadores, 2002) marcó en 2002 una referencia para las PPCC latinoamericanas, debido a que ahí se estableció una jerarquización de la dimensión cultural de las políticas públicas, proponiéndolas como herramientas para la inclusión social y la construcción de ciudadanía. En esta misma línea, el FA manifestó en su programa de gobierno que el derecho a la cultura es uno de los principales derechos humanos. En Argentina, el kirchnerismo promovió "una democratización de la cultura y un fortalecimiento de los derechos culturales para sectores invisibilizados de la sociedad. [...] dichas políticas ampliaron la definición de cultura [...] en relación con el Estado" (Fernández, 2020: 6).

Este enfoque de las PPCC latinoamericanas de principios del siglo xxI se basa en importantes antecedentes: por un lado, en la Conferencia Mundial sobre las Políticas Culturales (Unesco, 1982) se introduce una concepción de cultura más cercana a los DDCC y menos a las bellas artes. La misma se sostiene en aspectos como el respeto a la diversidad cultural, la revalorización del patrimonio inmaterial o el reconocimiento de los DDCC de los ciudadanos. Por el otro, el modelo de la democracia participativa de García Canclini (1987), que se funda en el reconocimiento de la pluralidad cultural y el derecho a desarrollar esas culturas.

En referencia al elemento simbólico y a la búsqueda de consenso para una transformación u orden social -propuestos por García Canclini (1987) en su definición de $\mathrm{PPCC}-$ resulta interesante lo planteado

8 “Argentina superó las 10.000 muertes por coronavirus", en La Diaria (7 de septiembre de 2020) <https://ladiaria.com. uy/politica/articulo/2020/9/argentina-supero-las-10000-muertes-por-coronavirus/> [15 de septiembre de 2020].

9 Según microdatos de la Encuesta Continua de Hogares 2019, 1.1\% de la población está sin cobertura (ni en los grandes sistemas ni en emergencias móviles) <http://www.ine.gub.uy/c/document_library/get_file?uuid=590504fd-5fOd42ff-a94c-fba714fb3f65\&groupId=1018> [10 de abril de 2020].

10 "Los datos del tercer trimestre muestran un crecimiento económico interanual de 0,9 \% y uno desestacionalizado de 0,6 \%, lo cual indica un movimiento al alza hacia niveles más altos aún, explicó el ministro de Economía y Finanzas, Danilo Astori. En ese marco, destacó las 'poderosas reservas internacionales, que llegan a más de 14.000 millones de dólares, equivalentes al $25 \%$ del producto interno bruto" (20 de diciembre de 2019) <https:/ /www.presidencia.gub.uy/comunicacion/ comunicacionnoticias / astori-crecimiento-economia-reservas-riesgo-pais> [10 de abril de 2020].

11 "Gobierno brasileño alerta sobre posible colapso del sistema de salud por el covid-19", en Xinhua Español (18 de marzo de 2020) <http: / / spanish.xinhuanet.com/2020-03/18/c_138889965.htm> [ 10 de abril de 2020].

12 "El FMI asegura que la deuda argentina "no es sostenible", en $D W$ (19 de febrero de 2020) <https://www.dw.com/es/ el-fmi-asegura-que-la-deuda-argentina-no-es-sostenible/a-52437384> [ 10 de abril de 2020]. 
por Fernández respecto de los gobiernos kirchneristas -extensible tal vez a otros gobiernos regionales-: "la producción de ciertos rasgos identitarios nacionales y latinoamericanistas en su política cultural. La dimensión simbólica se estructura fuertemente en la construcción de un mensaje de nación y de patria grande" (Fernández, 2020: 10).

En contraposición, el freno neoliberal en nuestra región se ha reflejado en cambios en las instituciones rectoras de las PPCC. En Argentina, desde su asunción en 2015, el gobierno de Cambiemos, encabezado por Mauricio Macri, transmitió un discurso basado en las ideas de ajuste y de ahorro, según señala Fernández: "la cultura y la educación fueron particularmente intervenidas en sus presupuestos, lo que implicó cierre de programas, la reconfiguración de la estructura administrativa, y, específicamente, una transformación en la orientación de las políticas culturales" (Fernández, 2020: 10). Uno de los momentos más claros del recorte a la institucionalidad cultural fue en 2018 , cuando se eliminó el Ministerio de Cultura -en un plan de ajuste presentado por el gobierno-relegándolo al rango de secretaría en el Ministerio de Educación (Yaccar y Sabatés, 2018).

Tras trece años de gobiernos del Pт, que tuvo en las políticas culturales una de sus áreas más desarrolladas, Michel Temer enfrentó en Brasil su primera crisis política al anunciar el fin del Ministerio de Cultura (MinC) y tuvo que retroceder; pero el primer día de gobierno de Jair Bolsonaro, en 2019, la cartera fue eliminada (Manevy, 2019). Actualmente la mayor referencia institucional cultural en Brasil es una Secretaría Especial, dependiente del Ministerio de Turismo, que al igual que el Ministerio de Salud se encuentra acéfala. En un trabajo académico referido al lugar de la cultura en los programas de gobierno presentados para las elecciones nacionales brasileñas en 2018 se señala, entre otras cosas, que en seis de los trece programas no se mencionó ninguna propuesta para la cultura y las políticas culturales del país, entre ellos está el programa del Partido Social Liberal (PSL) de Bolsonaro. ${ }^{13}$

En Uruguay, el nuevo gobierno propuso sumarle al Ministerio de Educación y Cultura (MEC) todo lo referido a Ciencia y Tecnología. ${ }^{14}$ Con el pretexto del ahorro y la optimización de los recursos, esto podría suponer un debilitamiento del aparato cultural público. En Argentina, en sentido opuesto, el retorno al progresismo en 2019 dio una fuerte señal de fortalecimiento de la institucionalidad cultural con la restauración del Ministerio de Cultura. ${ }^{15}$ De este modo, parecería retomarse la idea de un Estado fuerte y amplio para garantizar los DDCC de la ciudadanía.

\section{El caso uruguayo: las políticas culturales atravesadas por el cambio de gobierno y la pandemia}

El mes de marzo de 2020 en Uruguay se inició con un nuevo gobierno. Tras el resultado de las elecciones nacionales en 2019, el conservador Luis Lacalle Pou, perteneciente al PN pero liderando una coalición de cinco partidos políticos, se convirtió en el cuadragésimo segundo presidente de la República Oriental del Uruguay, poniendo fin a 15 años de gobiernos progresistas del FA.

En su discurso inaugural ante la Asamblea General, el presidente hizo una única mención a la cultura en referencia a la construcción de la democracia uruguaya: "La construyen también los intelectuales y los agentes culturales, que nos ayudan a entender el sentido profundo de nuestras decisiones" (Presidencia, 2020).

Exactamente 15 años antes, el $1^{\circ}$ de marzo de 2005, dando inicio al ciclo progresista, el presidente Tabaré Vázquez hacía también una única mención a la cultura en su discurso inaugural: "hay mucho para hacer en materia de igualdad racial, equidad de género, derechos del niño -iderechos del niño!-, derecho a la información, derecho a la cultura, derecho a un medio ambiente seguro. Esos también son derechos humanos que hacen a la calidad de la democracia" (Vázquez, 2005).

Estas citas podrían dar cuenta de dos concepciones diferentes de la cultura: mientras que en la primera, la cultura parecería estar asociada a cierta cualidad superior, propia de los intelectuales o agentes especializados; en la segunda, la cultura aparece integrada en una perspectiva de derechos humanos, propia de todos.

13 "Candidatos à presidência da República como Álvaro Dias (Podemos), Cabo Daciolo (Patriota), Henrique Meirelles (мDB), José Maria Eymael (DC), Vera Lúcia (PSTU), e por fim, o eleito presidente da República, Jair Bolsonaro (PSL), não fizeram nenhuma proposta de governo para a cultura e as políticas culturais no país. Mas, por que não fizeram? Falta de conhecimento ou comprometimento com as políticas culturais do país?” (Cabral, Rodrigues y Nascimento, 2019: 1592).

14 "Pablo Da Silveira anunció el cambio de nombre al MEc, que pasará a ser Ministerio de Educación, Cultura y Ciencia", en La Diaria (6 de marzo de 2020) <https: / / educacion.ladiaria.com.uy/articulo/2020/3/da-silveira-anuncio-cambio-denombre-al-mec-que-pasara-a-ser-ministerio-de-educacion-cultura-y-ciencia/> [1 de septiembre de 2020].

15 "Alberto Fernández anunció el próximo gabinete de Argentina", en La Diaria (7 de diciembre de 2019) <https://ladiaria. com.uy/articulo/2019/12/alberto-fernandez-anuncio-el-proximo-gabinete-de-argentina/> [10 de abril de 2020]. 
$\mathrm{Al}$ analizar diferentes modelos posibles para la acción cultural, García Canclini (1987) se refiere, entre otros, a dos de ellos que a nuestro juicio son pertinentes para este análisis: el de la democratización cultural y el de la democracia participativa.

El primero considera que la cultura es un bien superior al que se accede y, en tanto acción cultural, propone una serie de dispositivos para promover el acceso a la alta cultura. A propósito de la democratización cultural -criticando el "modelo francés"-Vincent Dubois señala: "no está diseñada en términos de diversificación de las formas culturales, en términos de expresión de la mayoría, ni en términos de promoción de la creatividad. Está diseñada en términos de acceso a bienes culturales escasos y de difusión de dichos bienes" (Dubois, 2016: 38-39).

El segundo, en cambio, está más asociado a la idea de $\mathrm{DDCC}$ en la medida en que también reconoce a los sujetos como productores de cultura. Si bien estos modelos no son puros en cuanto a su aplicación funcionan como una orientación de sentido para entender las PPCC. Al investigar los programas de gobierno del PN y del FA, presentados en las pasadas elecciones nacionales de 2019, encontramos referencias a las diferentes concepciones de cultura expresadas por los presidentes Vázquez (2005) y Lacalle Pou (2020), que podrían encuadrarse en los modelos propuestos por García Canclini: mientras que para el PN “el primer objetivo de las políticas culturales debe consistir en ampliar ese acceso a todos los uruguayos" (Partido Nacional, 2019) para el FA "la democracia necesariamente tiene una dimensión cultural en la que se expresan las diferencias y se construye la convivencia" (Frente Amplio, 2019: 147).

Desde este punto de vista, que vincula democracia y cultura -en la cual el Estado reconoce los DDCC de sus ciudadanos, no sólo en el acceso a bienes y servicios culturales sino también en su producción-, se constituyó el eje central de las PPCC impulsadas durante los gobiernos del FA (2005-2020). Su primera intención estuvo plasmada en el documento programático "Porque entre todos otro Uruguay es posible" (2003) donde se plantea la jerarquización del derecho a la cultura como uno de los componentes del núcleo irreductible de los derechos humanos. De este modo, como afirma Eduardo Nivón Bolán, la cultura, así como la educación, la vivienda o la salud, "ha pasado de ser un servicio prestado por el Estado a ser un derecho humano" y en esos términos "deben atender a otras condiciones que podríamos denomi- nar inicialmente como la dignidad humana" (Nivón Bolán, 2017: 254).

Definir "dignidad humana" es conceptualmente difícil, quizá, como nos propone Nivón Bolán, sea “el reconocimiento común que hemos decidido hacer los seres humanos [...] a nuestra propia existencia, la que dotamos de un mérito o valor." (Nivón Bolán, 2017: 254). Entonces, teniendo en cuenta ciertos aspectos subjetivos -¿qué mérito o valor tiene nuestra existencia?, ¿todas las existencias valen lo mismo?, ¿quiénes lo determinan?- podríamos señalar que la incorporación de esta dimensión no es privativa de la orientación ideológica de un gobierno, sino que, de acuerdo con su orientación, ella se expresa en mayor o menor medida en la política pública que impulsa. Es decir, en este caso, el FA colocó de manera explícita en sus programas, discursos y propuestas de gobierno la condición de la cultura como un derecho humano, intrínsecamente relacionada con la dignidad humana. Sin embargo, el nuevo gobierno, de orientación ideológica liberal, pone otros énfasis en cuanto a derechos $-\mathrm{y}$ por ende también en cuanto a la dignidad humana- que pasan de modo fundamental por la libertad y la propiedad. En consecuencia, el presidente Lacalle Pou se comprometió a:

respetar el derecho de todos [...] los derechos de hombres y mujeres de distintas creencias y orientaciones sexuales; los derechos de quienes están presos y los derechos de quienes se ven amenazados o son víctimas de delitos. Por supuesto que también los derechos de aquellos que combaten el crimen; los derechos de aquellos que no se animan a dejar su casa sola y los derechos de quienes no tienen una casa para vivir [Presidencia, 2020].

\section{Posibles efectos en la institucionalidad cultural}

También en el manejo de la institucionalidad pública -por acción u omisión- queda plasmada la orientación ideológica de cada gobierno. Con respecto a la institucionalidad cultural, el FA, casi al cierre del periodo, presentó ante el Parlamento un proyecto de Ley Nacional de Cultura y Derechos Culturales que, entre otros aspectos, proponía la constitución de un Ministerio de Cultura y Derechos Culturales, separado de Educación. Los tiempos parlamentarios no permitieron el tratamiento de esta propuesta que no encontró apoyo en el actual gobierno. ${ }^{16}$

\footnotetext{
16 "Para el Partido Nacional no es una prioridad crear un Ministerio de Cultura", en La Diaria (19 de agosto de 2019) <https: / /ladiaria.com.uy/articulo/2019/8/para-el-partido-nacional-no-es-una-prioridad-crear-un-ministerio-de-cultura> [10 de abril de 2020].
} 


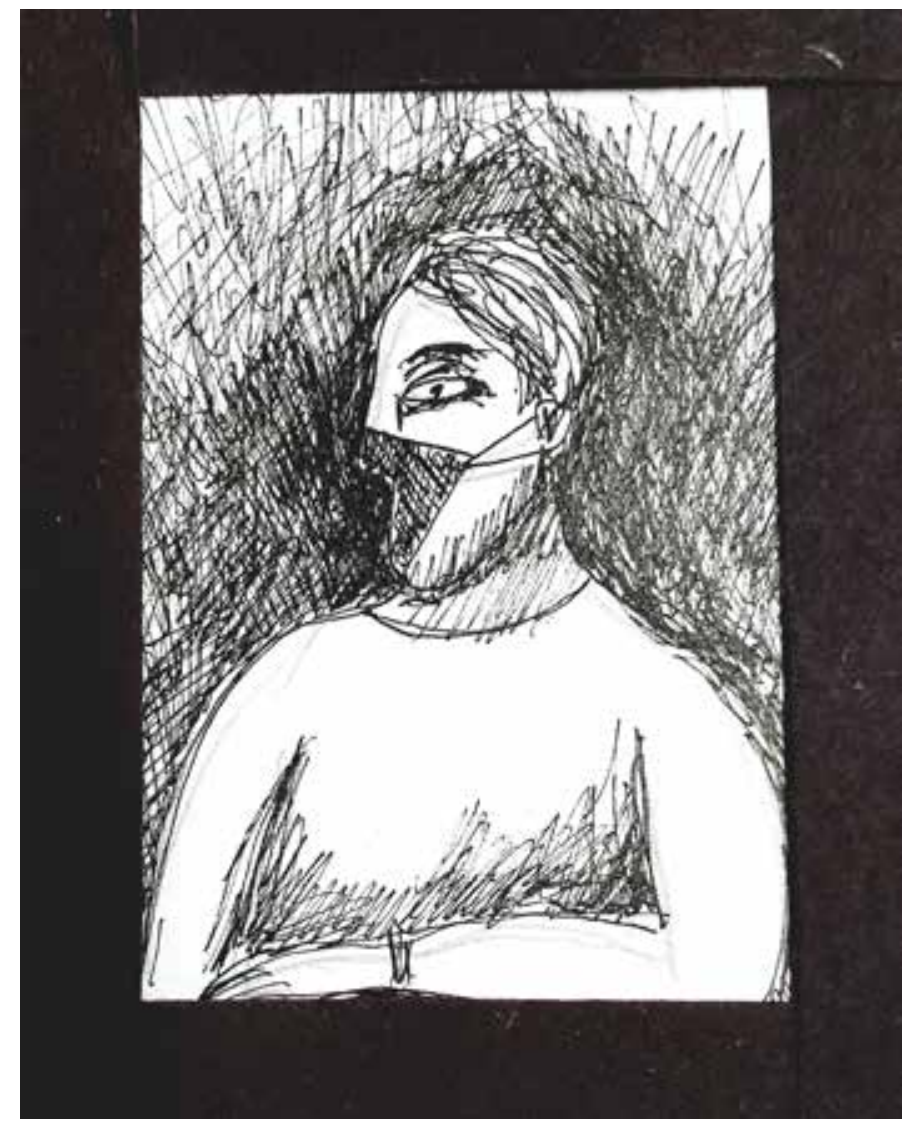

Más allá de la creación o no del ministerio, el mencionado proyecto de ley, tal como se expresa en su exposición de motivos (Achugar et al., 2018), buscaba dar coherencia institucional a la cultura y legitimar los avances que en políticas culturales se dieron en los últimos 15 años en el Uruguay. En un marco de ensanchamiento de la llamada "agenda de derechos", desde 2005, la institucionalidad cultural uruguaya tuvo importantes transformaciones que se sostuvieron sobre todo en dos aspectos: a) el reconocimiento de la ciudadanía cultural en el entendido de que cada ciudadano tiene derecho al acceso y a la producción de cultura, y b), como sostiene Mejía (2012), la necesidad de un Estado fuerte que garantice los derechos humanos y culturales de sus ciudadanos.

Para el actual gobierno, la educación en términos generales y en particular su vínculo con las tecnologías de la información y la comunicación (TIC) resultan prioritarias, de ahí que, el ministro de Educación y Cultura haya manifestado su intención de incorporar todo lo referente a ciencia y tecnología a la institucionalidad del Ministerio de Educación y Cultura (MEC). En este contexto, pensando de nuevo en la falta de apoyo a la propuesta de creación de un Ministerio de Cultura y Derechos Culturales -que para el fortalecimiento institucional de la cultura suponía la separación de Educación y el reconocimiento institucional de los derechos culturales- y en que a la institucionalidad actual del MEC se le propone agregar todo lo referente a la ciencia, parecería profundizarse aquello de "pobre cultura” que refirió Tomás de Mattos en relación con la debilidad institucional que supone por lo general un Ministerio de Cultura y algo más (Carámbula, 2011).

Hace unos pocos meses el poder ejecutivo envió al parlamento el proyecto de Ley de Presupuesto Nacional que regirá para el periodo 2020-2024. En su exposición de motivos define la institucionalidad cultural nacional con las siguientes palabras: "el rol rector ha estado tradicionalmente en manos del Ministerio de Educación y Cultura, principalmente a través de la Dirección Nacional de Cultura, el [Servicio Oficial de Difusión, Representaciones y Espectáculos] SODRE y el [Servicio de Comunicación Audiovisual Nacional] Secan (que gestiona la televisión y las radios públicas)" (Ministerio de Economía y Finanzas, 2020a: 145). Asimismo a modo de diagnóstico del estado de situación -responsabilidad del anterior gobierno- se establece: "En el terreno cultural, niveles de gasto público que han aumentado significativamente en los últimos años, pero bajo nivel de institucionalización, ausencia de criterios públicos que expliquen la ejecución de las diferentes políticas y muy escasas mediciones de impacto" (Ministerio de Economía y Finanzas, 2020a: 147). Entre los aspectos que resaltar de los logros recientes del gobierno se precisa que:

por primera vez en nuestra historia legislativa, la Ley de Urgente Consideración ${ }^{17}$ dio una estructura legal completa a la Dirección Nacional de Cultura del Ministerio de Educación y Cultura. [...] tras la aprobación de la Ley de Urgente Consideración (particularmente de su artículo 202) la Dirección Nacional de Cultura cuenta con una estructura de cinco institutos, todos ellos con sustento legal: 1) El Instituto Nacional de la Música [...]. 2) El Instituto Nacional de Artes Escénicas [...]. 3) El Instituto Nacional de Letras [...]. 4) El Instituto Nacional de Artes Visuales [...]. 5) El Instituto Nacional del Cine y el Audiovisual [...]. Esta estructura general y permanente no solo ayudará a dar coherencia y eficacia al conjunto de las políticas culturales, sino que garantizará formas de continuidad de la acción estatal por encima de la rotación de partidos en el ejercicio del gobierno [Ministerio de Economía, 2020a: 153-154].

\footnotetext{
${ }^{17}$ Ley $\mathrm{N}^{\circ}$ 19889. APROBACION DE LA LEY DE URGENTE CONSIDERACIÓN. LUC. LEY DE URGENCIA En IMPO (14 de julio
} de 2020) <https: / /www.impo.com.uy/bases /leyes / 19889-2020>. 
Se dice también que se está trabajando en el diseño de una red de Centros Nacionales de Cultura que se articularán con los institutos y “promoverán la accesibilidad de los bienes y servicios culturales; promoverán diferentes expresiones artísticas locales, nacionales e internacionales; y contribuirán a la descentralización y a la circulación cultural en todo el país" (Ministerio de Economía, 2020a: 154).

No obstante la preocupación expresada por la dimensión territorial de la política cultural -propuesta de los Centros Nacionales de Cultura-, en el artículo 336 del proyecto de ley presupuestal (Ministerio de Economía y Finanzas, 2020b) se propone suprimir la Unidad Ejecutora de "Centros MEC", lo que implica el desmantelamiento de una red de 127 centros culturales desplegados por todo el territorio nacional.

En un análisis sobre los Centros MEC en cuanto una política cultural con anclaje territorial, indicamos que su designación como Unidad Ejecutora suponía un fortalecimiento institucional. Asimismo señalamos sus principales objetivos: mejorar el acceso ciudadano a bienes culturales y oportunidades educativas, promoción de los derechos humanos, implementación de actividades de extensión, difusión y desarrollo artístico cultural, promover una mayor comprensión de la ciencia, tecnología e innovación y promover la alfabetización digital (Berger y Sequeira, 2018).

De la revisión de estos casos podría desprenderse la reafirmación del cambio de enfoque en la orientación de las PPCC que supuso la asunción del nuevo gobierno. El actual gobierno destaca el gasto excesivo, la mínima institucionalidad, la falta de criterio en la ejecución y las escasas mediciones de impacto de las PPCC. Planteó un ordenamiento institucional de la Dirección Nacional de Cultura con la creación de cinco institutos-Música, Artes Escénicas, Letras, Artes Visuales y de Cine y el Audiovisual-y para su articulación propuso una red de Centros Nacionales de Cultura que promuevan territorialmente la accesibilidad de los bienes y servicios culturales, promoción, descentralización y circulación de expresiones artísticas. Puso el énfasis en el acceso a los bienes y servicios culturales -democratización cultural- y decide cerrar los Centros MEC pensados como espacios de construcción de ciudadanía donde, además del acceso a la cultura, los ciudadanos eran reconocidos como productores de cultura-demo- cracia participativa. Esta concepción de DDCC queda aparentemente relegada, o al menos no explicitada, y no tiene lugar en la novel institucionalidad de la Dirección Nacional de Cultura. Los cinco institutos creados aluden a la cultura artística y ninguno se refiere a los DDCC o a la ciudadanía cultural, tampoco se manifiesta una institucionalidad transversal. Dicha concepción de democratización de la cultura - la alta cultura- corre el riesgo, a decir de Vincent Dubois (2016) de parecerse a un proyecto proselitista para convencer a la mayoría de que se sumen al culto a la cultura de las elites.

\section{La crisis de la Covid-19 en Uruguay}

Frente a la crisis de la COVID-19 se generaron tensiones entre las posturas de la actual coalición de gobierno y las de la oposición (FA). El planteamiento inicial del Sindicato Médico del Uruguay (smu) de declarar la cuarentena obligatoria fue descartado por el gobierno -en esencia por razones económicas-, pero la oposición lo apoyó y el presidente Lacalle Pou advirtió que decretar la cuarentena obligatoria sería un acto jurídico de gobierno y como tal debía hacerlo cumplir. Al respecto lanzó la pregunta de si quienes proponían la medida "están dispuestos a llevar detenido a un uruguayo en cualquier lugar del país que haya salido de su casa a tratar de hacer el peso". ${ }^{18}$ Por el contrario, el expresidente Vázquez reflexionó: "Cuando vivimos elementos extremos hay que priorizar, $y$ no hay nada más importante que la salud. Por tanto, cuando se encare este tema a futuro, obvio que hay que pensar en la economía, pero si tengo que priorizar elijo la vida y salud". ${ }^{19}$

Sin duda, ésta es una situación dinámica y compleja que provoca múltiples tensiones y opiniones diferentes, no obstante, la orientación ideológica del gobierno actuante se refleja también en cómo se maneja la crisis, qué cosas se priorizan y qué señales se dan a la población y al resto del mundo.

Por lo que toca a las PPCC y la COVID-19 el gobierno dio respuestas a la emergencia: realizó una encuesta sobre las necesidades del sector cultural, creó el Fondo Melogno y adelantó los llamados a Fondos Concursables, como las primeras acciones tomadas

\footnotetext{
18 "Lacalle Pou descartó la implementación de la cuarentena por el momento: No estamos haciendo política, estamos gobernando", en La Diaria" (23 de marzo de 2020) <https://ladiaria.com.uy/articulo/2020/3/lacalle-pou-descarto-laimplementacion-de-la-cuarentena-por-el-momento-no-estamos-haciendo-politica-estamos-gobernando/> [10 de abril de 2020].

19 "Tabaré Vázquez: Inevitablemente tenemos que ir a una cuarentena total si queremos cortar con este ciclo vicioso", en La Diaria (23 de marzo de 2020) <https://ladiaria.com.uy/articulo/2020/3/tabare-vazquez-inevitablemente-tenemosque-ir-a-una-cuarentena-total-si-queremos-cortar-con-este-ciclo-vicioso/> [10 de abril de 2020].
} 
frente a la pandemia. Entre las propuestas de difusión artística y contención para la población en la etapa de cuarentena el gobierno habilitó, mediante la Dirección Nacional de Cultura, una plataforma de difusión de contenidos culturales nacionales.

Después, con la incursión en la "nueva normalidad", poco a poco se fueron abriendo distintos espacios públicos. Los teatros fueron de los últimos en volver a operar, lo cual generó una fuerte tensión entre el gobierno y las gremiales artísticas. Finalmente se aprobó un protocolo para la reapertura de las salas -el cual no estuvo exento de críticas por algunas de las medidas propuestas-que fue la llave para destrabar el conflicto.

Si bien aún estamos frente a un panorama incierto en cuanto a la pandemia, a la luz de las primeras señales del gobierno en materia de PPCC -como lo contenido en la Ley de Urgente Consideración o en el Proyecto de Ley de Presupuesto Nacional 2020-2024 que analizamos en el apartado anterior-podríamos decir que las propuestas para la institucionalidad cul-

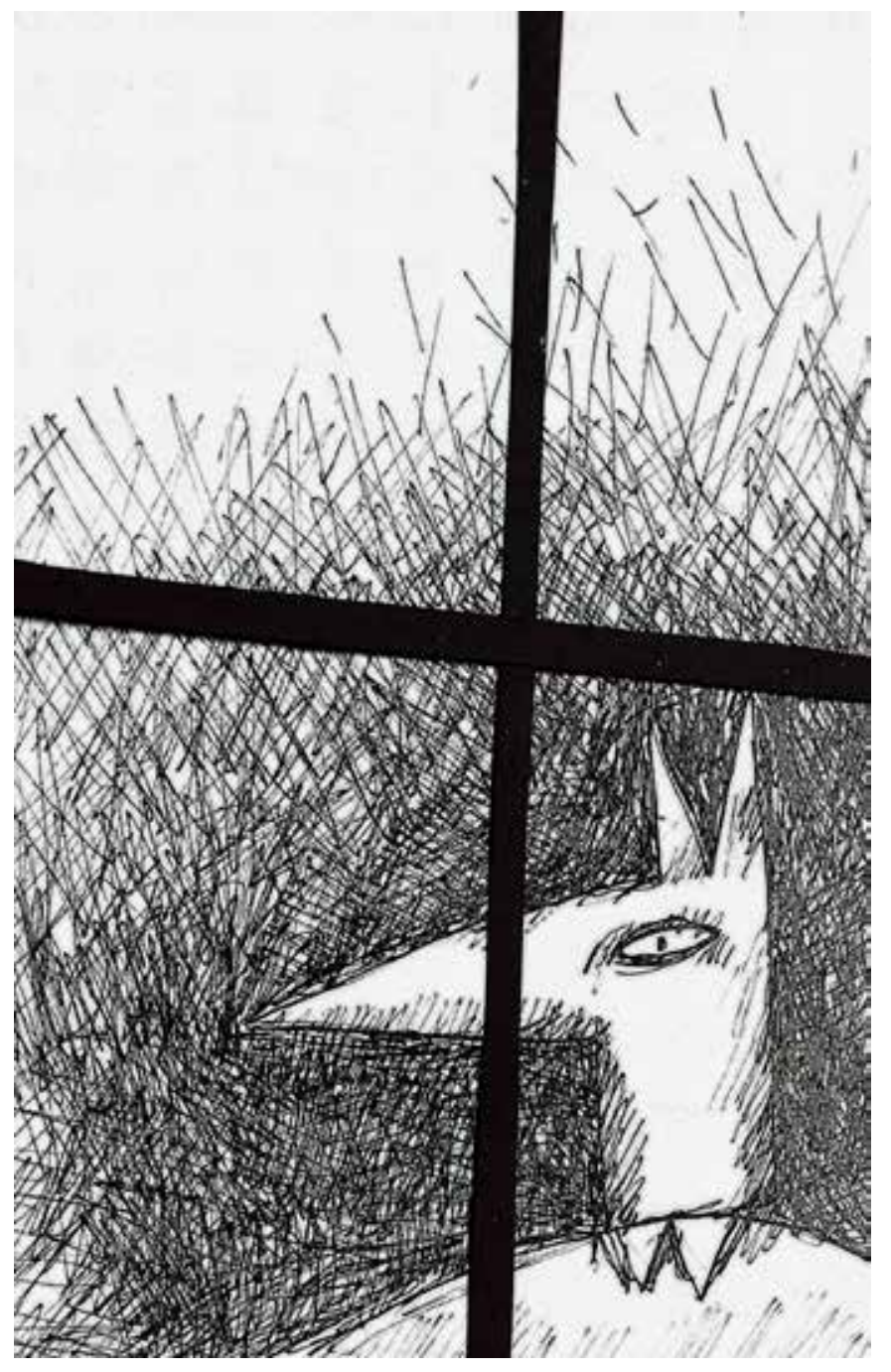

tural de los próximos años no instituyen medidas que fueron tomadas en una coyuntura de emergencia, pero que podrían tener utilidad para otras emergencias o constituirse como herramientas permanentes de apoyo para el sector, tal podría ser el caso del Fondo Melogno, el cual fue creado en abril de 2020 para mitigar los efectos de la pandemia en quienes trabajan en el sector cultural, al asignar $\$ 2952000$ a 189 artistas, productores y técnicos.

Así, la creación de institutos vinculados a la cultura artística o la suplantación de un programa territorial (Centros MEC), concebido como promotor de la ciudadanía cultural, por otro (Centros Nacionales de Cultura), pensado como instrumento para el acceso a bienes y servicios culturales, no sólo dan cuenta de un cambio de paradigma-donde el foco no está en los DDCC-, sino también de un Estado distante a las vulnerabilidades del sector, mismas que van más allá de la pandemia.

\section{Reflexiones finales}

A lo largo de este trabajo nos propusimos exponer cómo los cambios en la orientación ideológica del gobierno y la crisis de la covid-19 ocurridos a inicios de 2020 repercutieron en las PPCC uruguayas. Para ello, se consideró el contexto regional, caracterizado por los cambios en la orientación de los gobiernos en Argentina desde el 2015 y en Brasil desde el 2016.

Previo a los cambios de 2020, las PPCC uruguayas -desde la perspectiva progresista- se concibieron a partir de dos aspectos: 1) el reconocimiento explícito por parte del Estado de los DDCC de los ciudadanos, entendiendo que el desarrollo de la ciudadanía cultural pasa por garantizar tanto las posibilidades de acceso como de producción de cultura; y 2) la necesidad de Estados fuertes para garantizar el respeto y el ejercicio de los derechos culturales, entendidos éstos como derechos humanos.

La concepción del nuevo gobierno uruguayo en materia cultural -reflejada en la Ley de Urgente Consideración y en el Proyecto de Ley de Presupuesto Nacional 2020-2024- revela una posición en la cual las PPCC deben orientarse a garantizar el acceso a la cultura artística consagrada.

En consecuencia, podríamos suponer que nos enfrentamos a un cambio de paradigma en la concepción de las PPCC, transitando de uno que considera a los ciudadanos como consumidores y productores de cultura, a otro que los concibe principalmente como consumidores de dicha cultura consagrada.

Por lo que toca a la crisis provocada por la covid-19 y las PPCC en el Uruguay, nos centramos en dos aspec- 
tos: en las respuestas institucionales frente a dicha crisis sanitaria y en las posibles incidencias de ésta en la proyección de la institucionalidad cultural.

La pandemia generó múltiples respuestas del sector cultural tanto para mitigar los efectos económicos provocados por la emergencia como para generar contención a la población durante el distanciamiento físico y social. Como ya mencionamos, desde el gobierno se crearon instrumentos públicos de apoyo económico para el sector y se promovió la difusión de contenidos. Por lo anterior, podríamos concluir -más allá de las tensiones con los gremios de las artes escénicas- que la respuesta oficial fue mayormente adecuada.

A su vez, es importante resaltar que, en el contexto de la pandemia, muchas debilidades del sector cultural-sobre todo en cuanto a institucionalidad culturalquedaron de manifiesto. Entre ellas podríamos anotar la necesidad de: $a$ ) institucionalizar el reconocimiento de los derechos culturales de la ciudadanía; b) de dotar de coherencia a la institucionalidad cultural para un mejor manejo de los recursos y ejecución de la política pública; $c$ ) de fortalecer la descentralización territorial de la cultura; o d) de más formalización de los trabajadores de la cultura.

A pesar de esta constatación, en la proyección de las PPCC que propone el gobierno (expresada en la Ley de Urgente Consideración y en el Proyecto de Ley de Presupuesto Nacional 2020-2024) parecería no contemplarse el factor de incertidumbre que la pandemia supone ni el conjunto de debilidades institucionales ya precisadas. Por el contrario, las propuestas reflejan más la intención de instituir una nueva visión de la cultura que de consolidar herramientas para el fortalecimiento del sector. Tal podría ser el caso del Fondo Melogno -creado como respuesta a la emergencia sanitaria- que podría haberse instituido como una herramienta permanente de apoyo más allá del contexto pandémico.

Para enfrentar estos tiempos de incertidumbre, y si se tienen presentes tanto el papel que la cultura ha tenido en el contexto de la crisis sanitaria -fundamentalmente de contención de la población durante el confinamiento- como las respuestas creativas que han afectado de manera positiva la convivencia y el relacionamiento interpersonal tan deteriorados por la pandemia, pensamos que sería esencial fortalecer las PPCC. Por ende, su rol mediador entre los individuos y entre ellos y su entorno no sólo deberá tener en cuenta la crisis sanitaria sino también las perspectivas económicas mundiales -sin duda con mayor impacto en los países periféricos como los de nuestra región-, que no serán las mejores, y eso se verá reflejado en un aumento de la pobreza y la desigualdad.

\section{Fuentes}

Achugar, Hugo

2003 "Derechos culturales: ¿una nueva frontera de las políticas públicas para la cultura?", en Pensar Iberoamérica. Revista de Cultura. núm. 4, junio-septiembre <http://www.oei. es/historico/pensariberoamerica/ric04a04. htm $>$ [ 10 de abril de 2020].

Achugar, Hugo et al.

2018 "Ley Nacional de Cultura y Derechos Culturales", en Cuadernos del Claeh, segunda serie, año 37, núm. 107, pp. 427-333 <https://doi. org/10.29192/CLAEH.37.18> [ 10 de abril de 2020].

Berger, DAMIÁN

y FEDERICO SEgUeIRA

2018 "Centros mec. Análisis de una política pública cultural con anclaje territorial en el Uruguay de la última década”, en Encuentros Latinoamericanos, vol. II, núm. 1, pp. 39-54 <https: / / ojs.fhce.edu.uy/index.php/enclat/ article/view/72/84> [10 de septiembre de 2020].

Bordat-Chauvin, Elodie

2016 "Cultural policies and change: Mexico and $\mathrm{Ar}$ gentina after the neoliberal turn (1983-2012)", en Latin American Policy, vol. 7, núm. 1, pp. 147-162<https: / /www.researchgate.net/ publication/303089909_Cultural_Policies and_Change_Mexico_and_Argentina_after the Neoliberal Turn 1983-2012 Cultural Policies_and_Change $>$ [10 de septiembre de 2020].

Borón, Atilio

2001 "Sobre mercados y utopías: la victoria ideológico-cultural del neoliberalismo", en Cadernos de Estudos Sociais, vol. 17, núm. 2, pp. 179-188 <https: / / fundaj.emnuvens.com.br/ $\mathrm{CAD} /$ article/view/1279/999> [10 de abril de 2020].

Butler, Judith

2020 "El capitalismo tiene sus límites. Judith Butler", en Lobo Suelto, 19 de marzo <http: / / lobosuelto.com / el-capitalismo-tiene-suslimites-judith-butler/> [ 10 de abril de 2020 ]

BYUnG-Chul HaN

2020 "La emergencia viral y el mundo de mañana. Byung-Chul Han, el filósofo surcoreano que piensa desde Berlín", en El País, 22 de marzo <https://elpais.com/ideas/2020-03-21/ la-emergencia-viral-y-el-mundo-de-mananabyung-chul-han-el-filosofo-surcoreano-quepiensa-desde-berlin.html> $[10$ de abril de 2020].

Cabral, Eula Dantas Taveira, Karen B. Santarem

Rodrigues y Luana Matos do Nascimento

2019 "A cultura e as políticas culturais nos programas de governo de Bolsonaro e dos 12 candidatos à Presidência da República de 2018”, en Anais do X Seminário Internacional de Políticas Culturais, Fundação Casa de Rui Barbosa, Río de Janeiro, pp. 1585-1598 <http: / / rubi.casaruibarbosa.gov.br/handle / 20.500.1 1997/ 16423> [ 10 de abril de 2020].

Caetano, Gerardo,

Ernesto Nieto y Lucía Sellos

2020 "Elecciones 2019 en Uruguay: entre mutaciones y descontentos", en Gerardo Caetano 

Carámbula, Gonzalo

y Fernando Mayorga (coords.), Giros políticos y desafios democráticos en América Latina: enfoques de casos nacionales $y$ perspectivas de análisis, Consejo Latinoamericano de Ciencias Sociales, Buenos Aires, pp. 13-50 <http://biblioteca.clacso.edu.ar/ clacso/gt/20200409013440/Giros-politicosy-transformaciones-democraticas.pdf $>$ [ $10 \mathrm{de}$

2011 "La institucionalidad cultural pública como problema”, en Felipe Arocena (coord.), Regionalización cultural del Uruguay, Universidad de la República/Dirección Nacional de Cultura/Programa Viví Cultura, Montevideo, pp. 295-355 <https://otu.opp.gub.uy/ sites / default/files / docsBiblioteca / Arocena Regionalizacion_cultural_del_uruguay.pdf $>$ [ 10 de abril de $2 \overline{0} 20$ ].

Dubois, Vincent

2016 "El 'modelo francés' y su 'crisis': ambiciones, ambigüedades y retos de una política cultural", en Debats. Revista de Cultura, Poder y Sociedad, vol. 130, núm. 2, pp. 33-52<http:// revistadebats.net/article/view/1674/2441> [ 10 de septiembre de 2020].

Fernández, Clarisa

2020 "Estado y políticas culturales en Argentina. Un análisis comparativo entre el kirchnerismo y la Alianza Cambiemos (2007-2017)", en Sociohistórica, núm. 45, pp. 1-17 <https://doi. org/10.24215/18521606e102> [10 de abril

Frente Amplio de 2020].

2003 "Grandes lineamientos programáticos para el gobierno 2005-2010. Porque entre todos otro Uruguay es posible" <https://www.frente amplio.uy/documentos-institucionales / download/83/134/34> [10 de abril de 2020].

Frente Amplio

2019 Bases programáticas 2020-2025 <https:// www.frenteamplio.uy/noticias / todas-lasnoticias /item/902-nuestro-programa> [ $10 \mathrm{de}$ abril de 2020].

García Canclini, Néstor

1987 "Políticas culturales y crisis de desarrollo. Un balance latinoamericano", en Néstor García Canclini (ed.), Políticas culturales de América Latina, Grijalbo, México, pp. 13-61.

Hinkelammert, FranZ J.

1990 Democracia y totalitarismo, DEI, San José de Costa Rica.

KLein, NaOMI

2008 La doctrina del shock. El auge del capitalismo

Manevy, Alfredo del desastre, Paidós, Buenos Aires.

2019 "As políticas culturais - Bolsonaro, 100 dias", en Le Monde Diplomatique Brasil, 10 de abril $<$ https: / / diplomatique.org.br/as-politicasculturais-bolsonaro-100-dias/> [10 de abril de 2020].

Mejía, JuAn Luis

2012 ¿Derechos sin Estado? Tres momentos de la institucionalidad cultural en América Latina", en Euroamericano, Campus de Cooperación Cultural <https: / /www.oei.es / historico/ euroamericano/ponencias_derechos_ derechos.php> [ 10 de abril de 2020$]$.
Ministerio DE ECONOMÍA

Y FINANZAS

2020a Presupuesto Nacional 2020-2024. Mensaje y exposición de motivos, Ministerio de Economía y Finanzas, Montevideo <https:// medios.presidencia.gub.uy/legal/2020/ proyectos/08/cons_min_320_parte_1.pdf> [ 10 de septiembre de 2020].

Ministerio de ECONOMÍA

Y FINANZAS

2020b Presupuesto Nacional 2020-2024. Proyecto de ley, Ministerio de Economía y Finanzas, Montevideo <https://medios.presidencia.gub.uy/legal/2020/proyectos /08/cons_ min_320_parte_2.pdf>.

Nivón Bolán, EDUARDO

2017 "Derechos culturales y ciudadanía. Una reflexión desde la condición mexicana", en Periférica Internacional. Revista para el Análisis de la Cultura y el Territorio, núm. 17, pp. 251-258 <https: / / revistas.uca.es/index.php/ periferica/article/view/3280> [ 10 de abril de 2020].

PARTIDO NACIONAL

2019 Lo que nos une. Programa de gobierno 20202025, Partido Nacional, Montevideo <https: / / www.partidonacional.org.uy/media/ Programa-de\%20Gobierno-2019.pdf> [10 de abril de 2020].

Partido dos Trabalhadores

2002 "A imaginação a serviço do Brasil. Programa de Políticas Públicas de Cultura", <http:// rubi.casaruibarbosa.gov.br/handle / 20 . $500.11997 / 6287>$ [ 10 de abril de 2020].

PRESIDENCIA

2020 "Discurso completo del presidente Luis Lacalle Pou en la Asamblea General", en Uruguay Presidencia, 1 de marzo <https: / www. presidencia.gub.uy/comunicacion / comunicacionnoticias / lacalle-pou-discursocompleto-asamblea-general $>$ [10 de abril de 2020].

ROHTER, LARRY

2005 "With New Chief, Uruguay Veers Left, in a Latin Pattern", en The New York Times, 1o de marzo <https://www.nytimes.com/ 2005 / 03 / 01 / world / americas / with-newchief-uruguay-veers-left-in-a-latin-pattern. html > [ 10 de abril de 2020].

SanahuJa, José Antonio

2010 "Suramérica y el regionalismo posliberal", en Manuel Cienfuegos y José Antonio Sanahuja (eds.), Una región en construcción. UNASUR y la integración en América del Sur, Fundació СIDOB, Barcelona, pp. 87-135.

SanahuJa, José Antonio

2019 "El ascenso global de la ultraderecha y el nacionalismo: Crisis de la globalización, el regionalismo y el orden liberal", en Josette Altmann Borbón (ed.), América Latina frente a la reconfiguración global, Facultad Latinoamericana de Ciencias Sociales, San José de Costa Rica, pp. 31-64 <https://www.flacso.org/sites / default / files / Documentos / publicaciones / libro_geopolitica_global_flacso_2019.pdf> [10 de septiembre de 2020].

Svampa, Maristella

2006 "Movimientos sociales y nuevo escenario regional: Las inflexiones del paradigma neoli- 
beral en América Latina”, en Sociohistórica, núm. 19-20 <https://www.sociohistorica. fahce.unlp.edu.ar/article/view/SHn 19-20a 06> [ 10 de abril de 2020].

UNESCO

1982 Conferencia Mundial sobre las Políticas Culturales: informe final, Organización de las Naciones Unidas para la Educación, la Ciencia y la Cultura, París <https: / / unesdoc.unesco. org/ark:/48223/pf0000052505_spa> [ $10 \mathrm{de}$ abril de 2020].

VÁZgUez, TABARÉ

2005 "Discurso de toma de posesión", en Parlamento del Uruguay <https: / / parlamento.gub.uy/ documentosyleyes / discursos / presidentesrou /3714> [ 10 de abril de 2020].

YACCAR, MARÍA DANIELA

y PAUla SABatés

2018 "Cuando el ajuste llegó también a las políticas culturales", en Página 12, 30 de diciembre <https: / / www.pagina 12.com.ar/165198cuando-el-ajuste-1lego-tambien-a-las politicas-culturales $>$ [ 10 de abril de 2020].
ZAMORANO, MARIANO,

JoAguim RiUs Ulldemolins Y RicARdo Klein

2014 “¿Hacia un modelo sudamericano de política cultural? Singularidades y convergencias en Uruguay, Paraguay y Chile en el siglo xxi", en Revista Europea de Estudios Latinoamericanos y del Caribe, núm. 96, abril, pp. 5-34 <https://www.researchgate.net/ publication / 274380055 Hacia un modelo_sudamericano_de_politica_cultural_singularidades_y_convergencias_en_Uruguay_ Paraguay_y_Chile_en_el_siglo_XXI> [ 10 de septiembre de 2020].

ŽIŽEK, SLAVOJ

2020 "Coronavirus es un golpe al capitalismo al estilo de 'Kill Bill' y podría conducir a la reinvención del comunismo", en Sopa de Wuhan. Pensamiento contemporáneo en tiempos de pandemia, Editorial ASPO (Aislamiento Social Preventivo y Obligatorio), s.1., pp. 21-28 <https: / / www.elextremosur.com/files / content/23/23684/sopa-de-wuhan.pdf> [ $10 \mathrm{de}$ abril de 2020]. 